\title{
Lactobacillus paracasei biyokatalizörü ile enantiyosaf (S)-1- (4-metoksifenil) etanol üretimi
}

\author{
Production of enantiopure (S)-1-(4-methoxyphenyl) ethanol by Lactobacillus paracasei \\ biocatalyst
}

\section{Engin ŞAHIIN*1,a}

${ }^{1}$ Bayburt Üniversitesi, Sağlık Bilimleri Fakültesi, Beslenme ve Diyetetik Bölümü, 69000, Bayburt

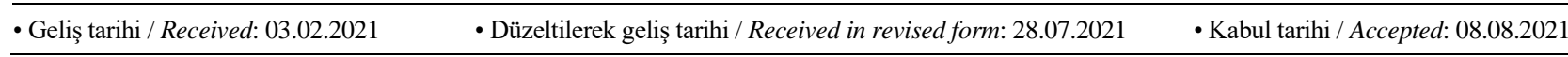

\begin{abstract}
Öz
Bu çalı̧̧mada, 4-metoksiasetofenonun enantiyoseçici indirgenmesinde yedi biyokatalizörün indirgeme kapasitesi tam hücre biyokatalizör olarak araştırılmıştır. Lactobacillus paracasei BD28'in en iyi indirgeme kapasitesine sahip olduğu bulunmuştur. $\mathrm{pH}$, inkübasyon süresi, çalkalama hızı ve sıcaklık gibi farklı parametrelerin enantiyomerik aşırlık ve dönüşüm üzerindeki etkileri araştıııldı. Tam hücre biyokatalizörü Lactobacillus paracasei BD28 kullanılarak, genel alerjik yanıt için tedavi fonksiyonuna sahip sikloalkil [b] indollerin sentezinde kullanılabilen $(S)$-1-(4-metoksifenil) etanol, gram ölçeğinde, yüksek verimli ve enantiyomerik olarak saf halde üretilmiştir. Gram ölçekli üretim gerçekleştirildi ve \% 95 verimle optik olarak saf formda 9,69 g (S)-1-(4-metoksifenil) etanol üretildi. Bu, kimyasal işlemlere kıyasla $(S)$ 1-(4-metoksifenil) etanol üretimi için ucuz, temiz ve çevre dostu bir işlemdir.
\end{abstract}

Anahtar kelimeler: Asimetrik indirgenme, Biyokatalizör, Kiral alkol, Lactobacillus paracasei, (S)-1-(4-metoksifenil) etanol

\begin{abstract}
In this study, the reductive capacity of seven biocatalysts were investigated as whole-cell biocatalyst in the enantioselective reduction of 4-metoxyacetofhenone. Lactobacillus paracasei BD28 was found to have the best reductive capacity. Effects of different parameters such as $\mathrm{pH}$, incubation time, agitation speed and temperature, on enantiomeric excess and conversion were investigated in a bioconversion. (S)-1-(4-methoxyphenyl) ethanol which, can be employed for the synthesis of cycloalkyl [b] indoles which have the treatment function for general allergic response, was produced in gram-scale, high yield and enantiomerically pure form using whole-cell biocatalyst of Lactobacillus paracasei BD28. The gram-scale production was carried out, and $9.69 \mathrm{~g}$ of (S)-1-(4-methoxyphenyl) ethanol in optically pure form was produced with $95 \%$ yield. This is a cheap, clean and eco-friendly process for production of (S)-1-(4-methoxyphenyl) ethanol compared to chemical processes.
\end{abstract}

Keywords: Asymmetric reduction, Biocatalyst, Chiral alcohol, Lactobacillus paracasei, (S)-1-(4-methoxyphenyl) ethanol

\footnotetext{
${ }^{*}$ Engin Şahin; esahin@bayburt.edu.tr, Tel: (0505) 69135 61, orcid.org/0000-0002-3723-1705
} 


\section{Giriş}

Kiralite, başta ilaç üretimi olmak üzere çok çeşitli endüstrilerde oldukça fazla dikkat çekmektedir. İlaç endüstrisinde kiraliteye artan ilgi ilaç formülasyonlarının üretiminde tekli enantiyomerlerin kullanılmasinı talep eden düzenleyici kurumlar tarafindan körüklenmektedir, çünkü enantiyomerlerin her biri farklı farmakolojik aktivitelere ve farklı biyolojik etkilere sahiptirler (Drayer, 1986; Murzin vd., 2005). Bundan dolay1 son yıllarda tek enantiyomer halinde ilaç satışlarında hızlı ve sürekli bir büyüme olmuştur. $\mathrm{Bu}$ bilgiler 1şığında, enantiyoseçici üretim metotlarının geliştirilmesi hızlı bir şekilde artmıştır ve yeni metotların geliştirilmesine devem edilmektedir (Ni ve Xu, 2012). Kiral sekonder alkoller ilaçların, zirai kimyasalların ve çoğu fonksiyonel molekülün sentezi için oldukça önemli öncü maddelerdir (Patel, 2002; Gamenara ve de María, 2009). Örneğin, kiral 1-(4-metoksifenil) etanol'ün her iki enantiyomeride çeşitli ilaçların sentezi için anahtar bir hammaddedir. $(S)$-1-(4metoksifenil) etanol ((S)-2), difenilhidramin hidroklorür ve loratadin dahil olmak üzere histaminlerin sentezi için önemli bir öncüdür (MacLellan ve Clayden, 2011; Brondani vd., 2012). Ayrıca, (S)-2, genel alerjik tepki için tedavi fonksiyonuna sahip olan sikloalkil [b] indollerin sentezi için kullanılabilir (Hillier vd., 2004, 2005). $(R)$-1-(4-metoksifenil) etanol ((R)-2), ibuprofen ve naproksen gibi aril propiyonik asit antienflamatuar ve analjezik ilaçların sentezi için temel bir öncü olarak kullanılabilmektedir (LlonaMinguez vd., 2015). Bu nedenle, kimyasal veya biyolojik metotlar kullanilarak enantiyosaf olarak (S)-2 ve $(\boldsymbol{R})$-2'nin sentezlenmesi oldukça önemli hale gelmiştir. Günümüzde enantiyosaf kiral sekonder alkoller kimyasal ve biyokatalizörler kullanılarak sentezlenebilmektedirler (Honda vd., 2017). Biyokatalizörler kiral bileşiklerin hazırlanması için çok başarılı olan ve yaygın olarak kullanılan bir metottur. Biyokatalizörlerin kimyasal katalizörlere kıyasla birçok avantajı vardır. Kimyasal katalizörler toksik atık ve çok çeşitli yan ürünler üretirken, biyokatalizörler biyolojik olarak parçalanabilir ve hafif reaksiyon koşulları altında kimyasal reaksiyonları gerçekleştirmek için temiz ve çevre dostu bir yol ve substrat için büyük bir seçicilik sağlamaktadırlar (Gotor-Fernández vd., 2006; Contesini vd., 2010). Biyokatalitik reaksiyonlar, birbirlerine göre hem avantajları hem de dezavantajları olan izole edilmiş saf enzimler ve tam hücre biyokatalizörler kullanılarak gerçekleştirilebilir (Kafarski ve Lejczak, 2004). İzole edilmiş saf enzimler, belirli reaksiyonları katalize ederek yan ürün oluşumunu veya ürün bozulmasını ortadan kaldırır ve ürünün saflaştırması genellikle çok daha kolaydır (Kafarski ve Lejczak, 2004). Ancak, saf enzimler çok pahalıdır ve çok kararsızdır. Buna ek olarak, enzimler tek bir reaksiyonu katalize ederken, çok sayıda endüstriyel ürün, tam hücreler kullanılarak bir dizi biyokimyasal reaksiyondan sonra elde edilir. Genel olarak, enzim saflaştırma, pahalı koenzim ve koenzim rejenerasyonu ilavesini önlemek için biyokatalizör olarak izole enzimler yerine tam mikrobiyal hücreler tercihli olarak kullanılmaktadır (Ishige vd., 2005). Tüm hücre biyokatalizörler çok daha kararlı, verimli, daha kolay ve uygun maliyetli olarak kullanılabilirler. $\mathrm{Bu}$ yüzden biyokatalizör olarak tam hücreler tercih edilmektedir (Şahin, 2017). Literatürde, 4metoksiasetofenon (1)'in biyokatalitik asimetrik indirgenmesine odaklanan, immobilize mikrobiyal hücreler tarafindan katalize edilen enantiyomerik olarak saf $(\boldsymbol{S})$-2'nin biyokatalitik sentezi hakkında bazı raporlar bulunmaktadır ve bunlar sinırlı sayıdadır (Lou vd., 2009; Wang vd., 2009; Świzdor vd., 2010). Bitki hücre kültürleri, mikrobiyal hücreler ve ketoreduktazlar gibi çeşitli biyokatalizörler, $\mathbf{1}$ 'in $(\boldsymbol{S})$-2'ye enantiyoseçici olarak indirgenmesi için uygulanmıştır (Lou vd., 2011; Wei vd., 2016). Bununla birlikte, düşük ürün verimi (\%63) ve enantiyomerik aşırılıkta (ee) (\%77) (S)-2 elde edilmiştir. Rasemik 2'nin çeşitli biyokatalizörler kullanılarak (S)-2'ye asimetrik olarak yükseltgendiği ve yüksek ee'lerin elde edildiği çeşitli çalışmalarda mevcuttur (Wang vd., 2009; Xu vd., 2015; Wei vd., 2016). Bununla birlikte, bu yaklaşım \%50 teorik verim ile sınırlıdır (Zong vd., 2019). Bu nedenle, (S)-2 ve (R)-2'yi daha yüksek verim, ee ve daha ekonomik olarak üretmek için kullanılabilecek bir tam hücre biyokatalizörü geliştirmek oldukça önemlidir.

$\mathrm{Bu}$ çalışmada daha önce boza içeceğinden elde edilmiş 7 farklı laktik asit bakterisi 4metoksiasetofenon (1)'in asimetrik indirgenmesinde biyokatalizör olarak kullanılabilme potansiyelleri değerlendirilmiştir. En iyi indirgeme kapasitesine sahip biyokatalizör belirlendikten sonra enantiyoseçiciliğe etki eden karıştırma hızı, pH, sıcaklık ve reaksiyon süresi gibi biyokatalitik indirgenme koşulları sistematik olarak optimize edilerek seçicilik üzerine etkileri kapsamlı bir şekilde incelenmiştir.

\section{Metaryal ve yöntem}

$\mathrm{Bu}$ çalışmada kullanılan kimyasallar ve MRS kültür ortamı Sigma-Aldrich'ten temin edildi. Elde edilen ürünün karekterizasyonu Bruker $400 \mathrm{MHz}$ NMR kullanılarak belirlenmiştir. Elde edilen ürünün enantiyomerik aşırılığı (ee) Agilent 1260 
model HPLC'de kiral kolon OD-H kullanılarak belirlenmiştir. Ürünün optik rotasyonu Bellingham+Stanley, ADP 220 model, dijital spektropolarimetre ile ölçülmüştür. Merck 60 silika jel (70-230), kolon kromatografisinde kullanılarak ürünün saflaştırma işlemi yapılmıştır. Reaksiyonların dönüşümleri bir miktar ham ürünün silikajel ihtiva eden küçük bir kolondan süzülmesi sonucunda HPLC analizi yapılarak keton pikinin alkol piki ile karşılaştırılması sonucu belirlenmiştir.

\section{1. Çalışmada kullanılan biyokatalizörler ve kültür şartlarl}

$\mathrm{Bu}$ çalışmada kullanılan biyokatalizler Lactobacillus plantarum BY14, Lactobacillus fermantum BY35, Enterecoccus faecium BY48, Lactobacillus paracasei BD28, Lactobacillus paracasei BD101, Lactobacillus paracasei BD71 ve Lactobacillus paracasei BD87 daha önce boza'dan izole edilmiştir. (Dertli vd., 2016). Biyokatalizörler MRS (\%2 glikoz, Twen $801 \mathrm{ml}$ $1^{-1}$, maya ekstraktı [Difco] $5 \mathrm{~g} \mathrm{1}^{-1}$, lab lemco [Oxoid] $8 \mathrm{~g} \mathrm{l}^{-1}$, pepton [Oxoid] $10 \mathrm{~g} \mathrm{l}^{-1}$, sodyum asetat. $3 \mathrm{H}_{2} \mathrm{O} 5 \mathrm{~g} \mathrm{l}^{-1}, \mathrm{~K}_{2} \mathrm{HPO}_{4} 2 \mathrm{~g} \mathrm{l}^{-1}$, triamonyum sitrat $2 \mathrm{~g} \mathrm{l}^{-1}$, tuz çözeltisi $\left[\mathrm{MgSO}_{4} .7 \mathrm{H}_{2} \mathrm{O} \% 11.5\right.$ $(w / v)$ ) ortamında $37^{\circ} \mathrm{C}^{\prime}$ de 2 gün geliştirildi ve daha sonra yıkama işlemi yapıldı. Yıkanan biyokatalizörler liyolifizatör ile dondurularak kurutuldu. Kurutulmuş biyokatalizörler kullanılmak üzere oda sicaklığında muhafaza edilmiştirler.

\subsection{Asimetrik biyoindirgenme için genel reaksiyon yöntemi}

$250 \mathrm{~mL}$ 'lik bir erlen içerisine $100 \mathrm{~mL}$ MRS besiyeri ve üzerine $20 \mathrm{mg}$ kuru Lactobacillus paracasei $\mathrm{BD} 28$ ilave edildi. Karışım çalkalayıcı inkübatörde $30^{\circ} \mathrm{C}$ 'de 2 saat 150 rpm'de karıştırıldı. Daha sonra karışımın pH'sı 1M'lı HCI kullanılarak 6.0'a ayarlandı ve aynı şartlar altında 2 saat daha karıştırılmaya devam edildi. Substrat 1 (1 mmol) reaksiyon karışımına ilave edilerek çalkalayıcı inkübatörde $30^{\circ} \mathrm{C}, 150 \mathrm{rpm}$ 'de 36 saat daha karıştırıldı. Karıştırma işlemi bittikten sonra karışımın kolay bir şekilde ektrakte edilebilmesi için santrifüjleme işlemine tabi tutuldu. Santrifüj işlemi sonrasında elde edilen sıvı kısım sodyum klörür ile doyuruldu. Daha sonra doyurulan sulu faz diklor metan ile ekstrakte edildi. Ekstraksiyon sonrasında elde edilen diklor metan fazı susuz magnezyum sülfat ile kurutuldu ve organik çözücü evaporasyon ile uzaklaştırıldı. Ham ürün kolon kromotgrafisinde hekzan-etil esatat (90:10) çözücü karışımı ile saflaştırıldı. Elde edilen kiral alkol (S)2'nin yapısı NMR ile karakterize edildi ve enantiyomerik aşırılık OD-H kiral kolon kullanılarak HPLC ile belirlendi.

\subsection{Gram ölçekte sentez yöntemi}

5 L'lik bir erlen içereisine 1 L'lik steril taze hazırlanmış MRS besiyeri ilave edilerek üzerine $200 \mathrm{mg}$ kuru Lactobacillus paracasei BD28 eklendi ve 2 saat $30^{\circ} \mathrm{C}$ 'de $150 \mathrm{rpm}$ 'de çalkalayıcı inkübatörde 2 saat karıştırıldı. Daha sonra pH 6'ya ayarlandı ve aynı şartlar altında 2 saat daha karıştırıldı. Bu karıştırma işleminden sonra, 4metoksi asetofenon (67 mmol, $10.06 \mathrm{~g}$ ) reaksiyon karışımına ilave edildi ve reaksiyon bittiğinde karekterizasyon ve saflaştırma işlemi yukarıda belirtildiği gibi gerçekleştirildi.

\subsection{Asimetrik biyoidirgenme ve reaksiyon şartlarının optimizasyonu}

Daha önce boza'dan izole edilen 7 farklı biyokatalizörün 4-metoksiasetofenon 1'in 1-(4metoksifenil) etanol 2'ye asimetrik indirgenme reaksiyonunda indirgeyici kapasiteleri değerlendirildi (Tablo 1). Biyokatalitik indirgenme, $20 \mathrm{mg}$ kuru biyokatalizörün 100 mL'lik taze MRS ortamında süspanse edilip üzerine $1 \mathrm{mmol}$ substrat $\mathbf{1}$ 'in ilave edilip 100 rpm'de 24 saat oda sıcaklığında karıştırılması ile gerçekleştirilmiştir. Yapılan bu değerlendirme reaksiyonlarının sonucunda dönüşüm ve enantiyomerik aşırılık bakımından en iyi biyokatalizör olarak Lactobacillus paracasei BD28 belirlendi. Belirlenen bu biyokatalizör kullanılarak seçiciliğe etki eden biyoindirgenme reaksiyon şartları optimize edilmiştir (Tablo 2). $\mathrm{Bu}$ optimize şartlar altında biyokatalizörün endüstriyel olarak kullanılabilirliğini test etmek için gram ölçekte substratların asimetrik indirgenmesi gerçekleştirilmiştir.

\section{Bulgular}

En iyi biyokatalizörü belirlemek için asimetrik indirgenme reaksiyonları $20 \mathrm{mg}$ kuru bakterinin $100 \mathrm{ml}$ taze hazırlanmış MRS besiyeri içerisine ilave edildi ve 2 saat oda sicaklığında, 100 rpm'de çalkalayıcı inkübatörde karıştırıldı. Daha sonra karışımın üzerine $1 \mathrm{mmol} 1$ eklendi ve aynı şartlar altında 24 saat karıştırıldı ve sonuçlar analiz edilerek en iyi biyokatalizör belirlendi (Tablo 1). 
Tablo 1. 4-metoksi asetofenon (1)'in asimetrik biyoindirgenmesinde en iyi biyokatalizörün belirlenmesi<smiles>COc1ccc(C(=O)CCCCCCCC(C)O)cc1</smiles>

1

(S)-2

(R)-2

\begin{tabular}{lccc}
\hline Biyokatalizör & Dönüşüm $^{\mathbf{a}}[\mathbf{\%}]$ & $\begin{array}{c}\text { Verimm }^{\mathbf{b}} \\
{[\mathbf{\%}]}\end{array}$ & $\mathbf{e e}^{\mathbf{c}}[\mathbf{\%}],\left(\boldsymbol{S}^{\mathbf{d}}\right.$ \\
\hline Lactobacillus plantarum BY14 & 49 & 47 & 50 \\
Lactobacillus fermantum BY35 & 51 & 48 & 55 \\
Enterecoccus faecium BY48 & 61 & 55 & 51 \\
Lactobacillus paracasei BD28 & 74 & 71 & 75 \\
Lactobacillus paracasei BD101 & 59 & 56 & 68 \\
Lactobacillus paracasei BD71 & 71 & 68 & 59 \\
Lactobacillus paracasei BD87 & 53 & 48 & 18 \\
\hline
\end{tabular}

Reaksiyon şartları: biyokatalizör $20 \mathrm{mg}$, substrat $1 \mathrm{mmol}$, RT, $24 \mathrm{~s}, 100 \mathrm{rpm},{ }^{\mathrm{a}}$ Dönüşümler kiral HPLC ile belirlendi, ${ }^{\text {bizole edilen verim, }{ }^{\mathrm{c}} \text { enantiyomerik }}$

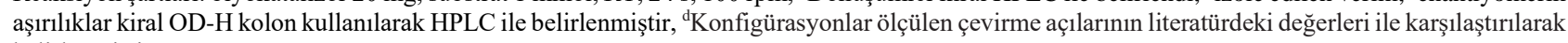
belirlenmiştir.

4-metoksi asetofenon'un 1-(4-metoksifenil) etanol 2'ye biyokatalitik asimetrik indirgenmesinde en iyi indirgenme potansiyeline sahip Lactobacillus paracasei BD28 biyokatalizörü belirlendikten sonra bu biyokatalizör kullanılarak reaksiyonun dönüșümü, ürünün seçicilik ve verimine etki eden reaksiyon koşulları ( $\mathrm{pH}$, karıştırma hızı, sıcaklık ve inkübasyon süresi) kapsamlı bir şekilde araştırılarak optimizasyonları yapılmıştır (Tablo 2).

Tablo 2. Lactobacillus paracasei BD28 biyokatalizörü kullanılarak asimetrik indirgenme şartlarının optimizasyonu

\begin{tabular}{|c|c|c|c|c|c|c|c|c|c|c|c|}
\hline \multicolumn{3}{|c|}{$\mathrm{pH}$} & \multicolumn{3}{|c|}{ Sicaklık } & \multicolumn{3}{|c|}{ İnkübasyon süresi } & \multicolumn{3}{|c|}{ Karıştırma Hızı } \\
\hline & $\begin{array}{l}\text { Dönş. } \\
(\%)^{\mathrm{a}}\end{array}$ & $\begin{array}{c}\text { ee } \\
(\%)^{b, c}\end{array}$ & ${ }^{\circ} \mathrm{C}$ & $\begin{array}{l}\text { Dönş. } \\
(\%)^{\mathrm{a}}\end{array}$ & $\begin{array}{c}\text { ee } \\
(\%)^{\mathrm{b}, \mathrm{c}}\end{array}$ & Saat & $\begin{array}{l}\text { Dönş. } \\
(\%)^{\mathrm{a}}\end{array}$ & $\begin{array}{c}\text { ee } \\
(\%)^{\mathrm{b}, \mathrm{c}}\end{array}$ & $\mathrm{rpm}$ & $\begin{array}{c}\text { Dönş. } \\
(\%)^{\mathrm{a}}\end{array}$ & $\begin{array}{c}\text { ee } \\
(\%)^{\mathrm{b}, \mathrm{c}}\end{array}$ \\
\hline 4.5 & 74 & $75(S)$ & RT & 88 & $91(S)$ & 24 & 95 & $96(S)$ & 100 & 99 & $98(S)$ \\
\hline 5.5 & 80 & $79(S)$ & 28 & 94 & $92(S)$ & 36 & 99 & $98(S)$ & 150 & 99 & $99(S)$ \\
\hline 6 & 88 & $91(S)$ & 30 & 95 & $96(S)$ & 48 & 99 & $89(S)$ & 200 & 65 & $54(S)$ \\
\hline 6.5 & 81 & $80(S)$ & 32 & 90 & $78(S)$ & 60 & 87 & $71(S)$ & 250 & 61 & $41(S)$ \\
\hline 7 & 77 & $71(S)$ & 34 & 83 & $69(S)$ & 72 & 79 & $65(S)$ & & & \\
\hline 7.5 & 65 & $63(S)$ & 36 & 78 & $54(S)$ & & & & & & \\
\hline
\end{tabular}

${ }^{\mathrm{a}}$ Dönüşümler kiral HPLC ile belirlendi, ${ }^{\mathrm{c}}$ enantiyomerik aşırılıklar kiral OD-H kolon kullanılarak HPLC ile belirlenmiştir, ${ }^{c}$ Konfigürasyonlar ölçülen çevirme açılarının literatürdeki değerleri ile karşılaştırılarak belirlenmiştir.

Reaksiyon şartları optimize edildikten sonra bu optimize şartlar altında biyokatalizör miktarının dönüşüm, enantiyomerik aşırılık ve verim üzerine etkisi araştırıldı (Tablo 3).

Tablo 3. Biyokatalizör miktarının dönüşüm ve seçiciliğe etkisi

\begin{tabular}{llll}
\hline Biyokatalizör miktarı (mg) & Dönüșüm (\%) & ee (\%) & Verim (\%) \\
\hline 10 & 82 & 79 & 77 \\
15 & 91 & 82 & 79 \\
20 & $>99$ & $>99$ & 95 \\
25 & 89 & 79 & 80 \\
30 & 82 & 65 & 77 \\
35 & 79 & 62 & 71 \\
40 & 77 & 58 & 69 \\
45 & 68 & 54 & 61 \\
50 & 65 & 51 & 58 \\
55 & 67 & 47 & 61 \\
\hline
\end{tabular}

Reaksiyon şartları: $\mathrm{pH} 6,30^{\circ} \mathrm{C}, 150 \mathrm{rpm}, 36 \mathrm{~h}$ 
Reaksiyon optimizasyon şartları belirlendikten sonra bu optimizasyon şartları altında biyokatalizörün endüstriyel olarak kullanılabilirliğini göstermek için değişik gram skalada substrat kullanılarak biyokatalizörün dönüşüm ve enantiyomerik aşırılığında herhangi bir değişiklik olmadan maksimum ne kadar substratı indirgeyebileceği tespit edildi (Şekil 1).<smiles>COc1ccc(C(C)=O)cc1</smiles>

$67 \mathrm{mmol}(10.06 \mathrm{~g})$

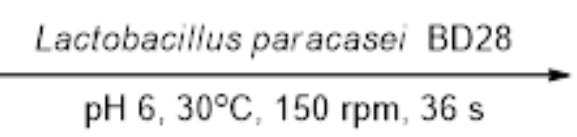

Dönüsüm $>\% 99$

ee $>\% 99$

verim: \%95<smiles>COc1ccc([C@@H](C)O)cc1</smiles>

(S)-2

$63.65 \mathrm{mmol}(9.69 \mathrm{~g})$

Şekil 1. (S)-1-(4-metoksifenil)ethanol'ün gram ölçekte sentezi

\subsection{Kiral sekonder alkol (S-2)'nin spektral verileri}

\subsection{1. (S)-1-(4-methoxyphenyl)ethanol ((S)-2)} (Şahin, 2017)

Renksiz sıv1, verim \%95; ${ }^{1} \mathrm{H}-\mathrm{NMR}(400 \mathrm{MHz}$, $\left.\mathrm{CDCl}_{3}\right) \delta=7.30-7.27(\mathrm{~m}, 2 \mathrm{H}), 6.89-6.85(\mathrm{~m}, 2 \mathrm{H})$, $4.83(\mathrm{q}, J=6.4 \mathrm{~Hz}, 1 \mathrm{H}), 3.79(\mathrm{~s}, 3 \mathrm{H}), 2.11$ (bs, $\mathrm{OH}), 1.46(\mathrm{~d}, J=6.5 \mathrm{~Hz}, 3 \mathrm{H})$ (Şekil 2); ${ }^{13} \mathrm{C}-\mathrm{NMR}$ $\left(100 \mathrm{MHz}, \mathrm{CDCl}_{3}\right) \delta 158.9,138.0,126.7,113.8$,
69.9, 55.3, 25.0 (SSekil 3); $[\alpha]_{\mathrm{D}}{ }^{25}=-61.6$ (c 1.0, $\left.\mathrm{CHCl}_{3}\right),>99 \%$ ee; Lit. $[\alpha]_{\mathrm{D}}{ }^{25}=+3.7\left(\mathrm{c} 1.0, \mathrm{CHCl}_{3}\right)$ $R$ enantiyomer ve \%6 ee için ölçülen değer) (Şahin, 2017); HPLC koşulları: kiral OD-H kolon, $220 \mathrm{~nm}$, akış kızı: $0.8 \mathrm{~mL} / \mathrm{dk}, i$-PrOH$/ n$-hekzan 5:95, $\mathrm{t}_{R}(S$ enantiyomer) $17.7 \mathrm{dk}$. (Şekil 4 (rasemik alkol 2'nin HPLC kromatogram1); Şekil 5). Substrat 1'in HPLC analiz şartları $(\boldsymbol{S})-2$ ile aynıdır ve ketonun alıkonma zamanı $11.2 \mathrm{dk}$. (Şekil 6).

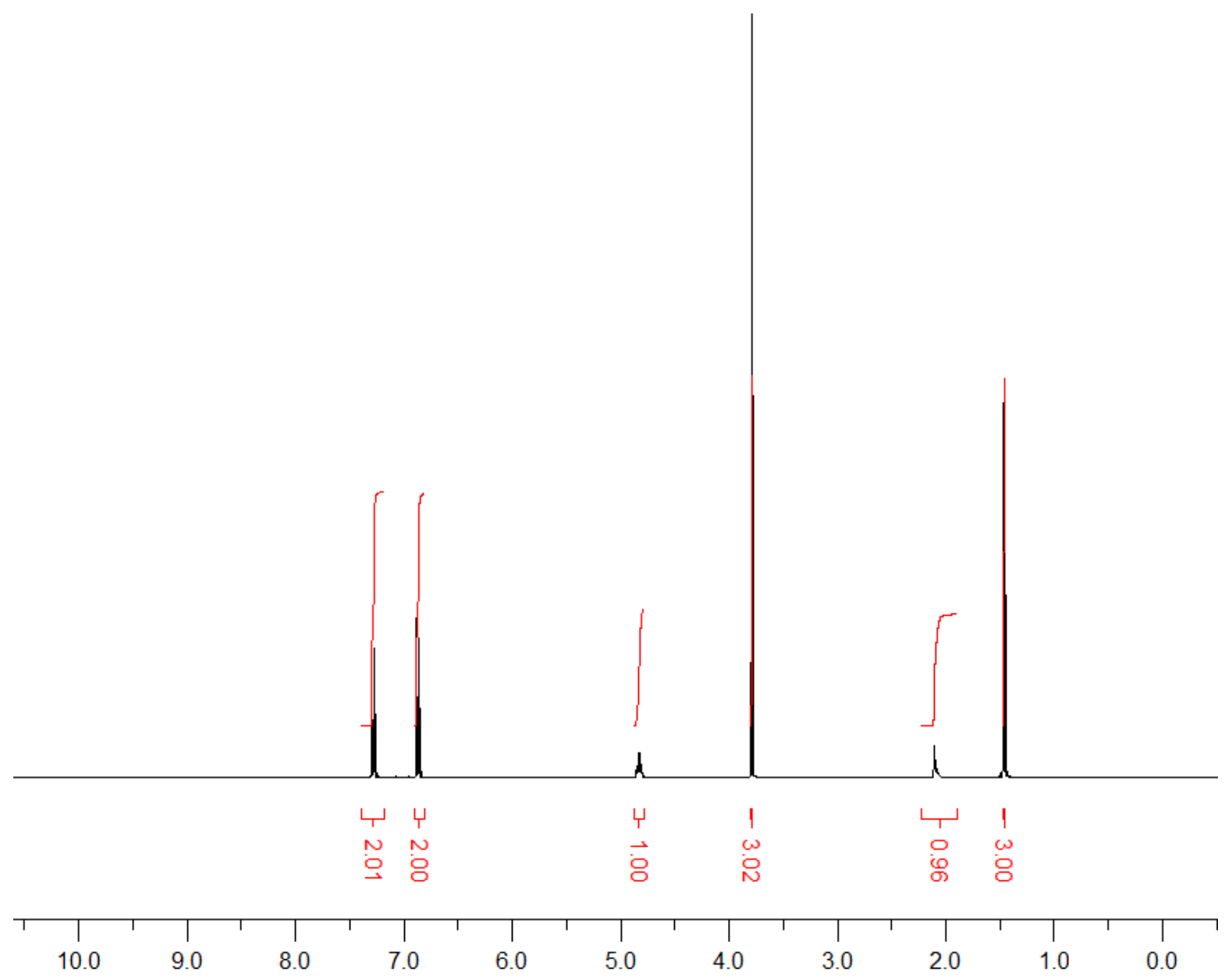

Şekil 2. (S)-2'nin ${ }^{1} \mathrm{H}$-NMR spektrumu 

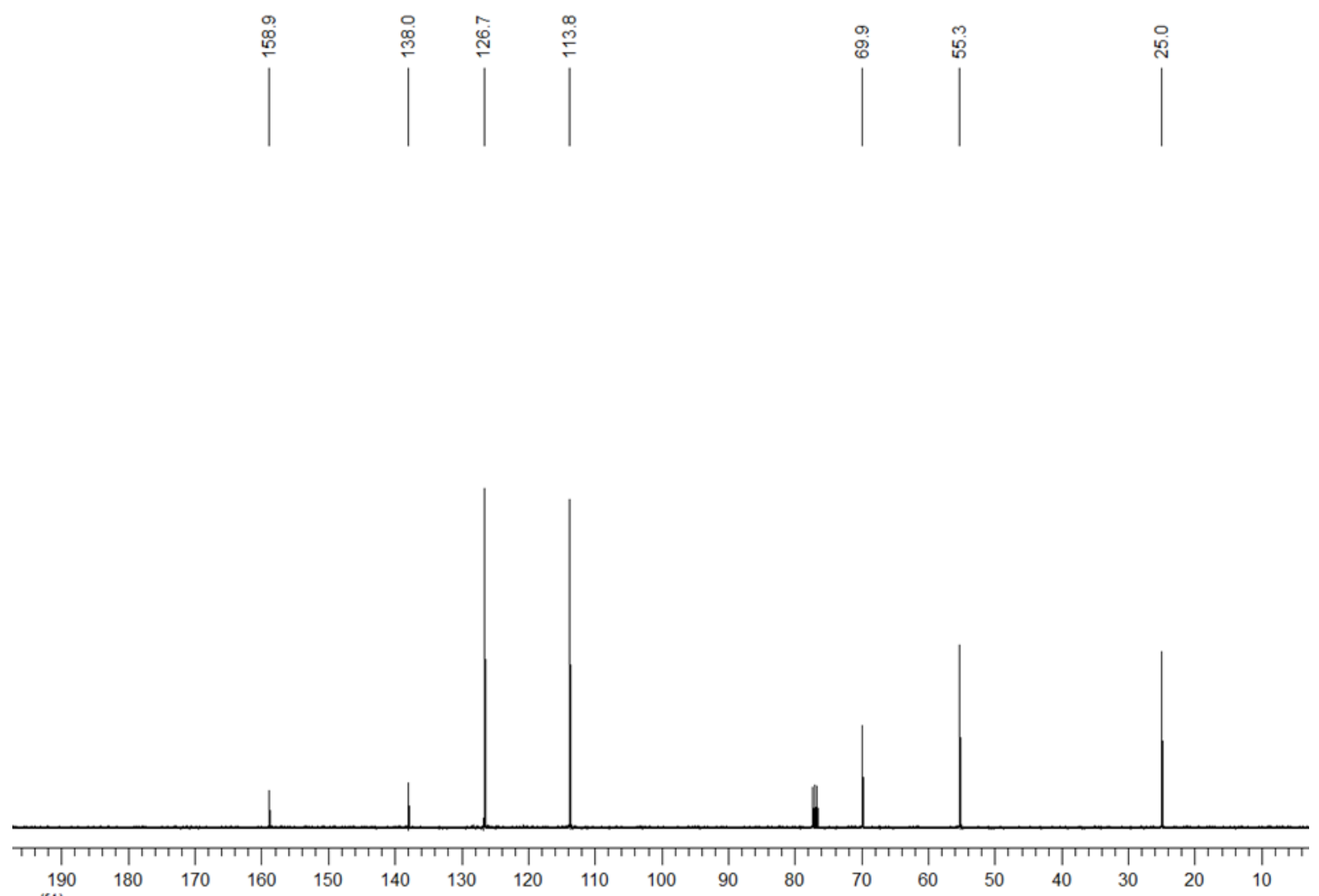

Şekil 3. (S)-2'nin ${ }^{13} \mathrm{C}-\mathrm{NMR}$ spektrumu

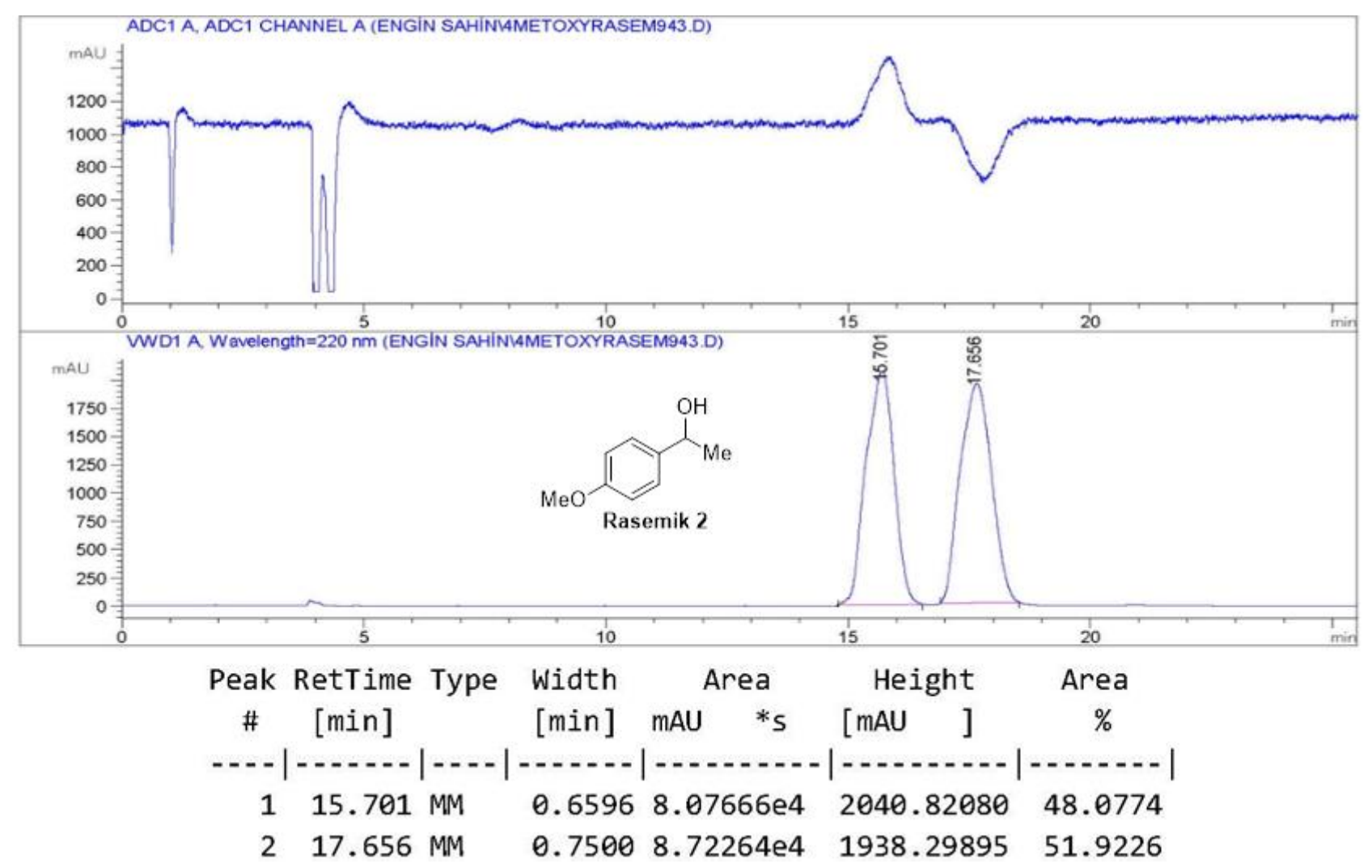

Şekil 4. Rasemik alkol 2'nin HPLC kromatogramı 


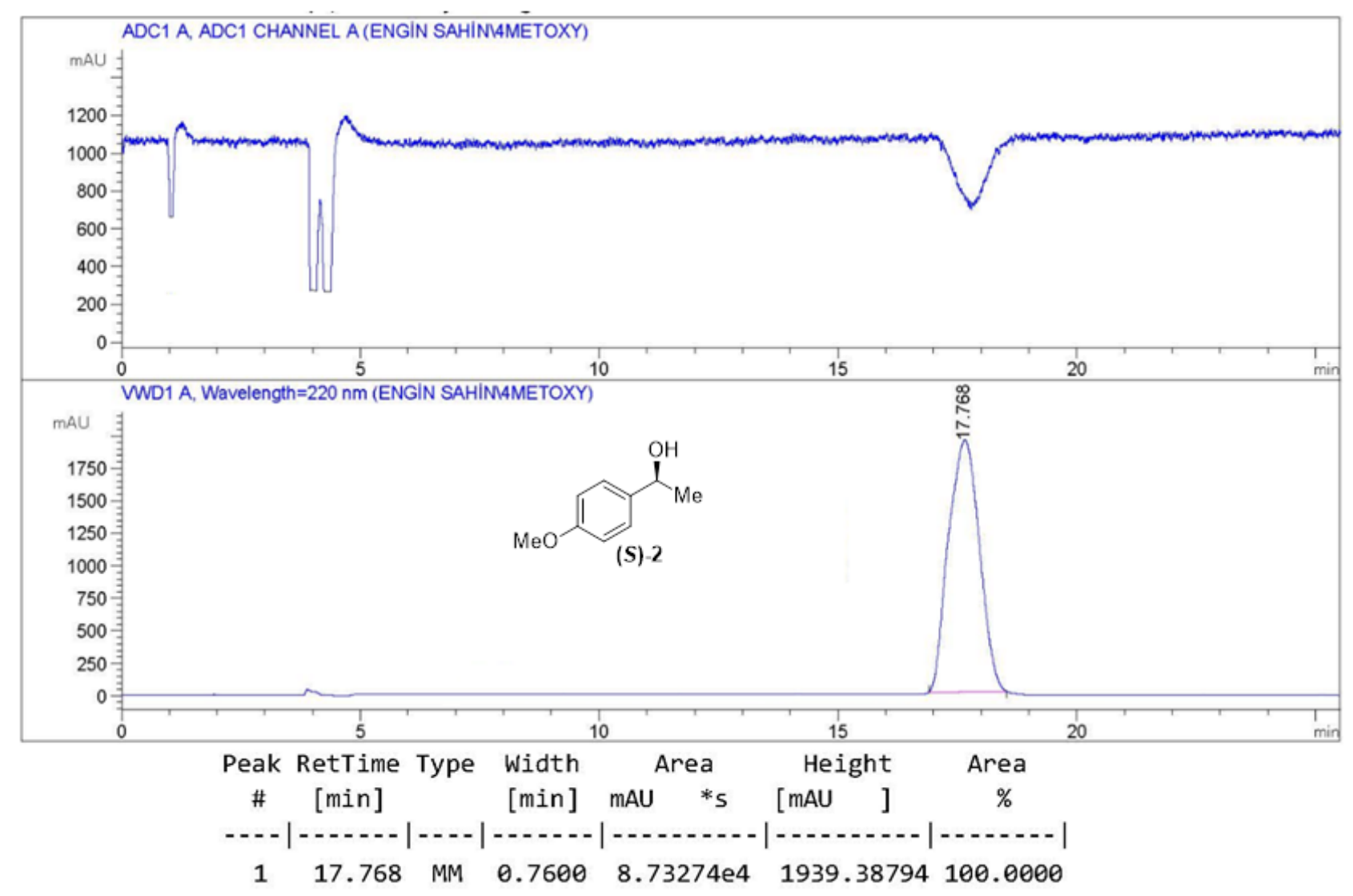

Şekil 5. (S)-2’nin HPLC kromatogramı

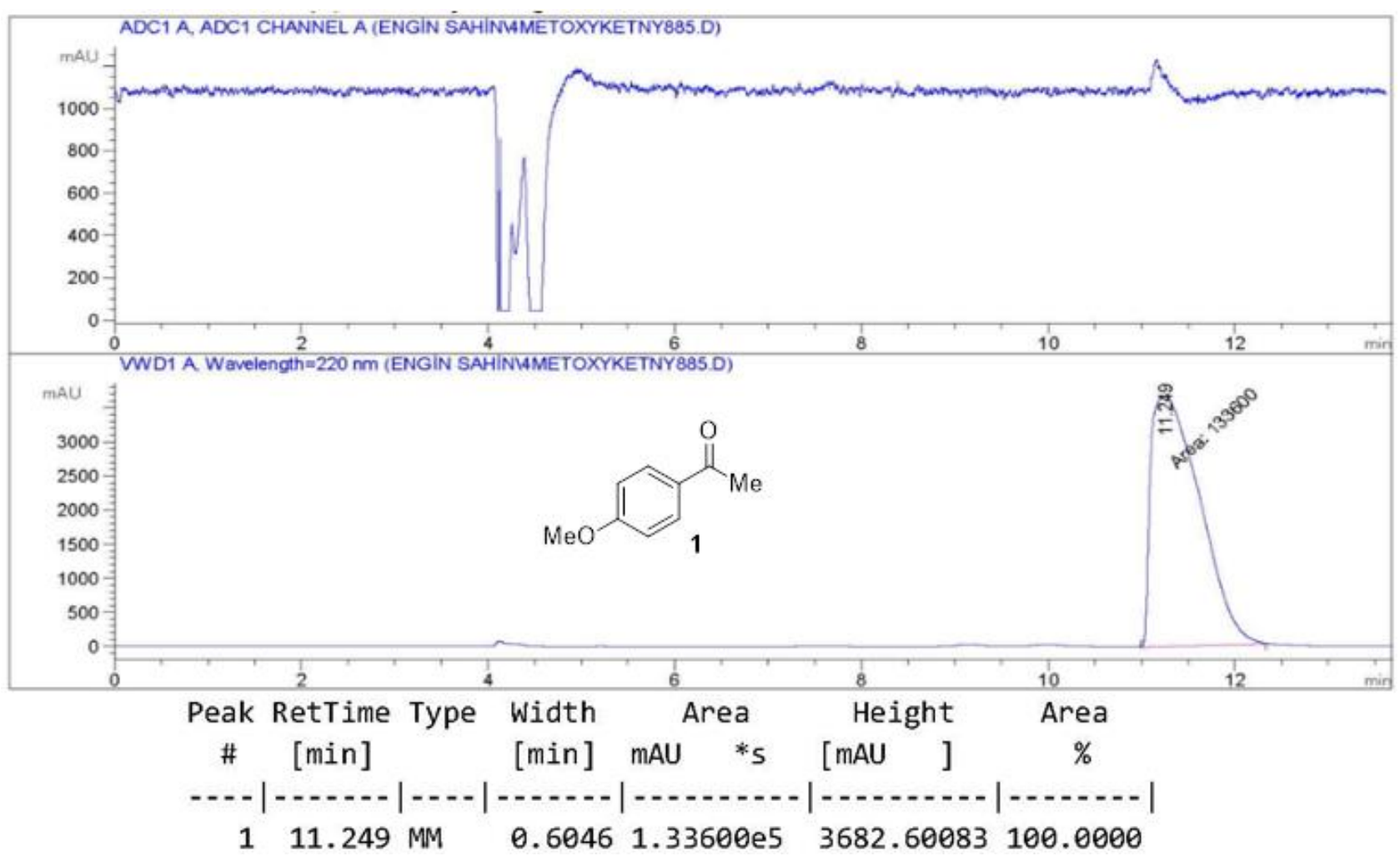

Şekil 6. Substrat 1'in HPLC kromatogramı 


\section{Tartışma ve Sonuç}

Çeşitli biyokatalizörlerin taranması sonucu arzulanan ee'yi ve dönüşümü elde etmek organik kimya için önemli bir yoldur (Matsuda vd., 2009). Bununla birlikte literatür iyi bir biyokatalizörün sahip olması gereken özellikleri tanımlamıştır (Matsuda vd., 2009). İyi bir biyokatalizöre fermantasyonun optimizasyonu kullanılarak ulaşılabilir. Biyokatalizörlere olan ilginin artmasindan dolay1, bilinen mevcut biyokatalizörler hala sınırlıdır ve bu nedenle yeni ve geliştirilmiş aktivitelere sahip yeni biyokatalizörlerin keşfedilmesi hayati önem taşımaktadır. Tablo 1'den açıkça görülmektedir ki kullanılan 7 farklı biyokatalizör \%49'dan \% 74'e kadar değişen bir dönüşüm oranı ve $\% 18$ 'den $\% 75$ 'e kadar değișen enantiyomerik aşırılıklarda (S)-2'yi üretmişlerdir (Tablo 1). Çeşitli biyoindirgenme reaksiyonlarından elde edilen enantiyomerik aşırılık ve dönüşüm değerleri, taranan 7 biyokatalizörden Lactobacillus paracasei BD28'nin en iyi ee'yi ve dönüşümü verdiğini ortaya koymaktadır. Bundan dolay 1 dönüşüm (\%74) ve enantiyomerik aşırılık bakımında (\%75) en iyi değere sahip olan Lactobacillus paracasei BD28 en iyi biyokatalizör olarak seçildi ve bundan sonraki reaksiyonlara bu biyokatalizör kullanılarak devam edildi. Reaksiyon koşulları, kiral bir alkolün başarılı bir şekilde üretilmesi için gereklidir ve $\mathrm{pH}$, sıcaklık, inkübasyon süresi ve çalkalama hızı gibi parametrelerin optimizasyonu yüksek dönüşüm ve enantiyomerik aşırılığa ulaşmak için önemlidir (Tablo 2) (Pereira, 1998). İlk parametre olarak pH'nın dönüşüm ve seçiciliğe etkisinin araştırılması yapılmıştır. pH'nın, tam hücrelerin kullanıldığı biyokatalitik reaksiyonların seyrinde anahtar bir rol oynadığı bilinmektedir ve aşağıda belirtildiği şekilde etkiler yapabilir. a) $\mathrm{pH}$, reaksiyona dahil olan enzimlerin aktivitesini ve enantiyoseçiciliğini etkiler. b) Koenzim rejenerasyonunu etkiler ve bu da substratlarm biyoindirgenmesini etkiler. c)Reaksiyona dahil olan substratların, ürünlerin ve enzimlerin iyonik durumunu değiştirir. d)Enzimin aktif bölgesinin substrat ile bağlanmasını etkiler (Guo vd., 2010; Luo vd., 2011; Cui vd., 2018). pH'nın etkisinin araştırılması için, $20 \mathrm{mg}$ kuru biyokatalizör, 1 mmol substrat, $100 \mathrm{rpm}$, oda sicaklığında (RT) ve 24 saat reaksiyon koşulları altında değişik $\mathrm{pH}$ 'larda (4.5-7.5) reaksiyonlar gerçekleştirilerek $\mathrm{pH}$ 'nı seçiciliğe etkisi araştırıldı (Tablo 2). Açık bir şekilde tablo 2'de görüldüğü gibi $\mathrm{pH}$ hem seçicilik hem de dönüşüm üzerine etkili olduğu görülmektedir. $\mathrm{pH}$ değerinin 6'nın üzerine çıktığ 1 durumlarda hem dönüşüm hem de seçicilik düşmektedir. Bu durum yukarıda da belirtildiği gibi enzimin üç boyutlu yapısının değişmesi sonucu enzim aktif merkezinin substrat ile yeterince etkileşememesi sonucu seçicilik ve dönüşümün düşmesi ile açıklanabilir. pH 6 olduğu durumda en iyi dönüşüm $(\% 88)$ ve en iyi seçicilik (\%91) değerlerine ulaşıldığ 1 için optimun $\mathrm{pH} 6$ olarak belirlenmiştir. Sıcaklık, çoğu enzimin aktivitesi, seçiciliği, kararlılığı ve bir reaksiyonun dinamik denge durumu üzerinde önemli bir etkiye sahiptir. Bu nedenle, biyoindirgenme reaksiyonları farklı sıcaklıklarda gerçekleştirilerek ikinci parametre olarak sicaklığın dönüşüm ve enantiyomerik aşırılık üzerine etkisi araştırıldı (Tablo 2). pH 6 olarak optimize edildikten sonra bu $\mathrm{pH}$ değerinde, $100 \mathrm{rpm}$ ve 24 saat reaksiyon süresi şartları altında sıcaklığın substratın dönüşümü, ürünün ee'si ve verimi üzerine etkisini belirlemek için farklı sicaklıklarda (RT-36 $6^{\circ}$ ) reaksiyonlar yapılmıştır. Sıcaklığın $30^{\circ} \mathrm{C}$ 'nin üzerine çıktığında hem dönüşüm hem de seçicilik değerleri düşmektedir. $\mathrm{Bu}$ değerlerdeki düşüş yüksek sicakliklarda biyokatalizörün aktivitesinin azalması ile açıklanabilir. Dönüşüm ve enantiyomerik aşırılık bakımından en iyi değerle $30^{\circ} \mathrm{C}$ 'de elde edildiği için $30^{\circ} \mathrm{C}$ optimum sicaklık olarak belirlenmiş ve bundan sonraki reaksiyonlar bu sıcaklıkta yapılmıştır. pH değerinin 6 ve sicaklığın $30^{\circ} \mathrm{C}$ olduğu ve karıştırma hızının100 rpm olduğu koşullar altında üçüncü parametre olan inkübasyon süresinin seçicilik ve dönüşüm üzerine etkisini incelemek için farklı inkübasyon sürelerinde (24-72 saat) reaksiyonlar gerçekleştirilmiştir (Tablo 2). Tablo 2'den de görüldüğü gibi reaksiyon süresinin 36 saatten fazla olduğunda hem seçiciliğin hem de dönüşümün düştügü görülmektedir. $\mathrm{Bu}$ değerlerdeki düşme süre arttıkça enzimin aktif bölgesinin şeklinin değişebileceği hem de enzim aktivitesinin azalması ile açıklanabilir. İnkübasyon süresi için en iyi dönüşüm (\%99) ve en iyi enantiyomerik aşırılık (\%98) 36 saatte elde edilmiştir ve bundan dolayı optimum inkübasyon süresi olarak 36 saat belirlenmiştir. Genel olarak, çalkalama hızı, biyoindirgenme sürecinde substratların ve ürünlerin partikül transfer oranını etkileyebilir ve daha sonra dönüşüm ve verimi etkiler. Bu nedenle, çalkalama hızının biyoindirgenme üzerindeki etkilerini araştırmak oldukça önemlidir. Bundan dolayı, karıştırma hızı enzimin yapısını değiş̧irdiği için son parametre olarak optimizasyonu yapılmıştır. pH'nın 6 , sıcaklığın $30^{\circ} \mathrm{C}$ ve inkübasyon süresinin 36 saat olduğu reaksiyon şartları altında farklı karıştırma hızları altında (100$250 \mathrm{rpm}$ ) reaksiyonlar yapılarak dönüşüm ve enantiyomerik aşırılık üzerine etkisi değerlendirilmiştir (Tablo 2). Karıştırma hızının 
150 rpm'den fazla olduğu durumlarda seçicilik ve dönüşüm oranı azalmaktadır. Bu azalma karıştırma hızı yüksek olduğunda biyokatalizörün yapısının değişmesi sonuçu aktivitesinin düşmesi ile açıklanabilir. Reaksiyonun tamamen dönüştüğü ve ürünün enantiyomerik aşırılığının \%99'dan büyük olduğu çalkalama hızı 150 rpm'dir. Bundan dolayı optimum çalkalama hızı $150 \mathrm{rpm}$ olarak belirlenmiştir. Sistematik olarak yapılan reaksiyon optimizasyon işlemi sonucunda en iyi biyoindirgenme reaksiyon koşulları (sıcaklık $30^{\circ} \mathrm{C}$, $150 \mathrm{rpm}, \mathrm{pH}$ 6, inkübasyon süresi 36 saat) belirlenmiştir. Tam hücre biyokatalizörlerinde, biyokatalizör miktarı yalnızca reaksiyon hızını, dönüşümü, seçiciliği doğrudan etkilemekle kalmaz, aynı zamanda kütle transferi sınırlamasını da başlatabilir. $\mathrm{Bu}$ nedenle, uygun miktarda biyokatalizör kullanarak biyokatalitik reaksiyonların gerçekleştirilmesi son derece önemlidir (Pu vd., 2011). Bu amaçla, 10 ila $55 \mathrm{mg}$ arasında değişen miktarlarda biyokatalizörler kullanılarak optimize edilmiş koşullar altında çeşitli deneyler gerçekleştirildi (Tablo 3). Biyokatalizör miktarı 20 mg'a kadar kullanıldığında dönüşüm ve ee'nin arttığı, ancak miktar 20 mg'dan fazla olduğunda hem dönüşüm hem de ee'nin azaldığı görülmüştür. Örneğin biyokatalizör miktarı $25 \mathrm{mg}$ ve $30 \mathrm{mg}$ olarak kullanıldığında ee'nin sirasıyla \% 79 ve\% 65'e düştüğü görülmüştür. $\mathrm{Bu}$ durum, daha önce literatürde belirtildiği gibi, reaksiyon ortamındaki biyokatalizörün artması ile NADPH miktarının değişmesi sonucu biyokatalizörün seçiciliğinin değişmesi ile açıklanabilir (Zhimin vd., 2018). Bundan dolayı bu biyokatalitik asimetrik indirgenme için uygun biyokatalizör miktarı $20 \mathrm{mg}$ olarak belirlenmiştir.

Çalışmanın son amacı, enantiyosaf kiral alkolün yeşil yöntemle gram ölçeğinde sentezlenmesi endüstriyel uygulamalar için son derece önemli olduğundan, belirlenen optimum biyoindirgenme koşullarını kullanarak (S)-2'nin gram ölçeğinde sentezini gerçekleştirmektir. Substrat konsantrasyonunun, ürünün ee'si ve substrat'ın dönüşümü üzerinde bir etkisi olduğu bilinmektedir. Literatürde, daha yüksek substrat konsantrasyonunun, hücre toksisitesine ve ürün/substrat inhibisyonuna neden olarak biyotransformasyonu azaltabileceği rapor edilmiştir (Xie vd., 2009; Singh vd., 2012). Bu nedenle, maksimum ee ve dönüşüm elde etmek için optimum substrat konsantrasyonunu belirlemek çok önemlidir. Substrat konsantrasyonu, reaksiyonun dönüşümünü ve seçiciliğini etkilemiştir çünkü hücreler, substrata karşı farklı afiniteye sahip farklı türde redüktazlar içerir.
Ayrıca, büyük miktarlarda substrat kullanılması hücre toksisitesine ve substrat ürün inhibisyonuna neden olabilir (Roy vd., 2003). Bu nedenle, optimum substrat konsantrasyonunun belirlenmesi çok önemlidir. Optimize edilmiş koşullar altında substrat konsantrasyonunun 10-80 mmol aralığında değiştirilmesiyle bir dizi deney gerçekleştirildi. Ürünün en iyi ee'si (>\% 99) ve tam dönüşüm (>\%99), $67 \mathrm{mmol}(10.06 \mathrm{~g}) / 1 \mathrm{~L}$ substrat 1 konsantrasyonu ile elde edildi (Şekil 1). Optimize edilmiş koşullar altında substrat 1 (67 mmol),>\% 99 ee ve \% 95 verimle $(\boldsymbol{S})$-2 $(63.65 \mathrm{mmol}, 9.69$ g)'ye dönüştürüldü. Dönüşüm ve ee, 67 mmol'den daha yüksek konsantrasyonda keton kullanılması ile azaldı. Dönüşüm ve ee'deki bu azalma substratın toksisitesinin bir sonucu olarak enzimin aktivitesindeki azalma ile açılanabilir.

Sonuç olarak, Lactobacillus paracasei BD28'in mükemmel dönüşüm ve enantioseçicilik ile 1'in asimetrik biyoindirgenmesi için çok önemli bir biyokatalizör olduğu gösterilmiştir. Difenilhidramin hidroklorür ve loratadin dahil olmak üzere intihistaminlerin sentezi için önemli bir öncü olarak kullanılabilen (S)-2, Lactobacillus paracasei BD28 kullanılarak gram ölçeğinde, mükemmel verimde ve enantiyomerik olarak saf formda sentezlendi. Bu çalışma, daha yüksek substrat tolerans1 $(10.06 \mathrm{~g} / 1 \mathrm{~L})$ ve verim $(\% 95)$ gibi avantajlar sağlamıştır. Bu sonuçlar, mevcut yöntemin gram ölçeğinde $(\boldsymbol{S})$-2'nin yeşil sentezi için önemli bir potansiyele sahip olduğunu göstermektedir. Bu biyokatalitik indirgeme, çevre dostu reaksiyon koşulları nedeniyle optik olarak saf (S)-2'nin sentezi için büyük önem taşımaktadır. Lactobacillus paracasei BD28 kullanılarak 1'in katalitik asimetrik indirgemesi, kimyasal işlemlere kıyasla ucuz, çevreye zarar vermeyen ve kolayca ölçeklendirilebilen bir metottur. Böylece, ilaç öncüsü olarak kullanılabilecek enantiyo saf $(\boldsymbol{S})$ 2'nin elde edilmesi için yeni bir biyokatalizör literatüre kazandırılmıştır.

\section{Teşekkür}

Biyokatalizörleri temininden dolayı Dr. Enes Dertli’ye (Yıldız Teknik Üniversitesi) ve HPLC analizlerinden dolayı Bayburt Üniversitesi Merkezi Araştırma Laboratuvarına teşekkür ederiz.

\section{Kaynaklar}

Brondani, P.B., Guilmoto, N.M., Dudek, H.M., Fraaije, M.W. and Andrade, L.H. (2012). Chemoenzymatic approaches to obtain chiralcentered selenium compounds. Tetrahedron, 68 , 10431-10436.

https://doi.org/10.1016/j.tet.2012.09.087 
Contesini, F.J., Lopes, D.B., Macedo, G.A., da Graça Nascimento, M. and de Oliveira Carvalho, P. (2010). Aspergillus sp. lipase: potential biocatalyst for industrial use. Journal of Molecular Catalysis B: Enzymatic, 67, 163-171. https://doi.org/10.1016/j.molcatb.2010.07.021

Cui, Y.H., Wei, P., Peng, F., Zong, M.H. and Lou, W. Y. (2018). Efficient biocatalytic stereoselective reduction of methyl acetoacetate catalyzed by whole cells of engineered E. coli. RSC Advances, 8 , 9970-9978. https://doi.org/10.1039/C8RA00883C.

Dertli, E., Mercan, E., Arıc1, M., Yılmaz, M.T. and Sağdıç, O. (2016). Characterisation of lactic acid bacteria from Turkish sourdough and determination of their exopolysaccharide (EPS) production characteristics. LWT-Food Science and Technology, 71, 116-124. https://doi.org/10.1016/j.lwt.2016.03.030.

Drayer, D.E. (1986). Pharmacodynamic and pharmacokinetic differences between drug enantiomers in humans: an overview. Clinical Pharmacology \& Therapeutics, 40, 125-133. https://doi.org/10.1038/clpt.1986.150

Gamenara, D. and de María, P.D. (2009). Candida spp. redox machineries: An ample biocatalytic platform for practical applications and academic insights. Biotechnology Advances, 27, 278-285. https://doi.org/10.1016/j.biotechadv.2009.01.00 5

Gotor-Fernández, V., Brieva, R. and Gotor, V. (2006). Lipases: Useful biocatalysts for the preparation of pharmaceuticals. Journal of Molecular Catalysis B: Enzymatic, 40, 111-120. https://doi.org/10.1016/j.molcatb.2006.02.010

Guo, J.L., Mu, X.Q. and Xu, Y. (2010). Integration of newly isolated biocatalyst and resin-based in situ product removal technique for the asymmetric synthesis of $(R)$-methyl mandelate. Bioprocess and Biosystems Engineering, 33, 797-804. https://doi.org/10.1007/s00449-009-0401-2

Hillier, M.C., Desrosiers, J.N., Marcoux, J.F. and Grabowski, E.J. (2004). Stereoselective carboncarbon bond formation via the mitsunobu displacement of chiral secondary benzylic alcohols. Organic Letters, 6, 573-576. https://doi.org/10.1021/o10363801

Hillier, M. C., Marcoux, J. F., Zhao, D., Grabowski, E. J., McKeown, A. E. and Tillyer, R. D. (2005). Stereoselective formation of carbon- carbon bonds via $\mathrm{SN}_{2}$-displacement: synthesis of substituted cycloalkyl [b] indoles. The Journal of Organic Chemistry, 70, 8385-8394. https://doi.org/10.1021/jo051146p
Honda, K., Inoue, M., Ono, T., Okano, K., Dekishima, Y. and Kawabata, H. (2017). Improvement of operational stability of Ogataea minuta carbonyl reductase for chiral alcohol production. Journal of bioscience and Bioengineering, 123, 673-678. https://doi.org/10.1016/j.jbiosc.2017.01.016

Ishige, T., Honda, K. and Shimizu, S. (2005). Whole organism biocatalysis. Current Opinion in Chemical Biology, 9, 174-180. https://doi.org/10.1016/j.cbpa.2005.02.001

Kafarski, P. and Lejczak, B. (2004). Application of bacteria and fungi as biocatalysts for the preparation of optically active hydroxyphosphonates. Journal of Molecular Catalysis B: Enzymatic, 29, 99-104. https://doi.org/10.1016/j.molcatb.2003.12.013

Llona-Minguez, S., Ghassemian, A. and Helleday, T. (2015). Lysophosphatidic acid receptor (LPAR) modulators: the current pharmacological toolbox. Progress in Lipid Research, 58, 51-75. https://doi.org/10.1016/j.plipres.2015.01.004

Lou, W.Y., Wang, W., Li, R.F. and Zong, M.H. (2009). Efficient enantioselective reduction of 4'methoxyacetophenone with immobilized Rhodotorula sp. AS2. 2241 cells in a hydrophilic ionic liquid-containing co-solvent system. Journal of Biotechnology, 143, 190-197. https://doi.org/10.1016/j.jbiotec.2009.07.004

Luo, F., Lu, D. and Gong, Y. (2011). Enantioselective bioreduction of 2-fluoro-2-alken-1-ols mediated by Saccharomyces cerevisiae. Journal of Molecular Catalysis B: Enzymatic, 70, 101-107. https://doi.org/10.1016/j.molcatb.2011.02.011

MacLellan, P. and Clayden, J. (2011). Enantioselective synthesis of tertiary thiols by intramolecular arylation of lithiated thiocarbamates. Chemical Communications, 47, 3395-3397. https://doi.org/10.1039/C0CC04912C

Matsuda, T., Yamanaka, R., and Nakamura, K. (2009). Recent progress in biocatalysis for asymmetric oxidation and reduction. Tetrahedon: Asymmetry, 20, 513-557. https://doi.org/10.1016/j.tetasy.2008.12.035

Murzin, D.Y., Mäki-Arvela, P., Toukoniitty, E. and Salmi, T. (2005). Asymmetric heterogeneous catalysis: science and engineering. Catalysis Reviews, 47, 175-256. https://doi.org/10.1081/CR-200057461

Ni, Y. and Xu, J.H. (2012). Biocatalytic ketone reduction: a green and efficient access to enantiopure alcohols. Biotechnology advances, 30 , 1279-1288. https://doi.org/10.1016/j.biotechadv.2011.10.00 7 
Patel, R.N. (2002). Microbial/enzymatic synthesis of chiral intermediates for pharmaceuticals. Enzyme and Microbial Technology, 31, 804-826. https://doi.org/10.1016/S0141-0229(02)00186-2

Pereira, R.D.S. (1998). The use of baker's yeast in the generation of asymmetric centers to produce chiral drugs and other compounds. Critical reviews in biotechnology, 18, 25-64. https://doi.org/10.1080/0738-859891224211

$\mathrm{Pu}, \mathrm{W}$., Huizhen, S., Liming, S., Junyao, H. and Yaping, L.Ü. (2011). Asymmetric bioreduction of 3, 5-bis (trifluoromethyl) acetophenone to its corresponding alcohol by Candida tropicalis. Chinese Journal of Chemical Engineering, 19, 1028-1032. https://doi.org/10.1016/S10049541(11)60087-6

Roy, A., Bhattacharyya, M.S., Kumar, L.R., Chawla, H.P.S. and Banerjee, U.C. (2003). Microbial reduction of 1-acetonapthone: a highly efficient process for multigram synthesis of S (-)-1-(1'napthyl) ethanol. Enzyme and Microbial Technology, 33, 576-580. https://doi.org/10.1016/S0141-0229(03)00178-9

Singh, A., Chisti, Y. and Banerjee, U.C. (2012). Stereoselective biocatalytic hydride transfer to substituted acetophenones by the yeast Metschnikowia koreensis. Process Biochemistry, 47, 2398-2404. https://doi.org/10.1016/j.procbio.2012.09.022

Świzdor, A., Janeczko, T. and Dmochowska-Gładysz, J. (2010). Didymosphaeria igniaria: a new microorganism useful for the enantioselective reduction of aryl-aliphatic ketones. Journal of Industrial Microbiology and Biotechnology, 37, 1121-1130. https://doi.org/10.1007/s10295-0100759-9

Şahin, E. (2017). Debaryomyces hansenii as a new biocatalyst in the asymmetric reduction of substituted acetophenones. Biocatalysis and Biotransformation, 35, 363-371. https://doi.org/10.1080/10242422.2017.1348500

Wang, B., Zhu, B., Gong, J., Weng, J., Xia, F. and Liu, W. (2020). Resolution of racemic1-(4methoxyphenyl) ethanol using immobilized lipase with high substrate tolerance. Biochemical Engineering Journal, 158, 107559. https://doi.org/10.1016/j.bej.2020.107559

Wang, W., Zong, M.H. and Lou, W.Y. (2009). Use of an ionic liquid to improve asymmetric reduction of 4'-methoxyacetophenone catalyzed by immobilized Rhodotorula sp. AS2. 2241 cells. Journal of Molecular Catalysis B: Enzymatic, 56 , 70-76. https://doi.org/10.1016/j.molcatb.2008.05.010

Wei, P., Liang, J., Cheng, J., Zong, M. H. and Lou, W.Y. (2016). Markedly improving asymmetric oxidation of 1-(4-methoxyphenyl) ethanol with Acetobacter sp. CCTCC M209061 cells by adding deep eutectic solvent in a two-phase system. Microbial Cell Factories, 15, 1-11. https://doi.org/10.1186/s12934-015-0407-1

Xie, Y., Xu, J.H., Lu, W.Y. and Lin, G.Q. (2009). Adzuki bean: a new resource of biocatalyst for asymmetric reduction of aromatic ketones with high stereoselectivity and substrate tolerance. Bioresource Technology, 100, 2463-2468. https://doi.org/10.1016/j.biortech.2008.11.054

Xu, P., Cheng, J., Lou, W.Y. and Zong, M.H. (2015). Using deep eutectic solvents to improve the resolution of racemic 1-(4-methoxyphenyl) ethanol through Acetobacter sp. CCTCC M209061 cell-mediated asymmetric oxidation. RSC Advances, 5, 6357-6364. https://doi.org/10.1039/C4RA12905A

Zhimin, O., Ma, L., Niu, Y. and Cui, J. (2018). Preparation of (R)-(-)-mandelic acid by two-step biotransformation of ethyl benzoylformate. Biocatalysis and Biotransformation, 36, 409416. https://doi.org/10.1080/10242422.2017.1420063

Zong, C., Zhang, X., Yang, F., Zhou, Y., Chen, N., Yang, Z. and Tang, Y. (2019). Biotransformation of a crizotinib intermediate using a mutant alcohol dehydrogenase of Lactobacillus kefir coupled with glucose dehydrogenase. Preparative Biochemistry and Biotechnology, 49 , 578-583. https://doi.org/10.1080/10826068.2019.1591987 